and maculoanesthetic forms of the disease, and in the vaseular endothelium. They have been demonstrated often in the ganglionic cells of the posterior root ganglia and of the spinal cord. Their occurrence in these cells leads Metchnikoff to say that the latter have phagocytic properties.

In view of the chronic course of leprosy and the absence of signs of intoxication over considerable periods, it seems probable that the bacillus secretes little or no Endotoxin (?). soluble toxin. From time to time, however, patients with tubercular leprosy develop fever, which may persist for weeks or months and eventually terminate in death. During such attacks the nodules not infrequently enlarge, become soft and later disappear. Lie conceives that such periods represent massive infection of the blood with the bacilli, and that at this time the latter undergo extensive disintegration and liberate endocellular toxins to which the toxic phenomena are due. It is a remarkable fact that intercurrent infections, as measles and smallpox, and the administration of potassium iodid, cause a similar enlargement, softening and final disappearance of leprous nodules, accompanied by marked degenerative changes in the bacilli. Hansen is of the opinion that the fever induced by these conditions has an actual curative effect, although its influence is not readily analyzed. He quotes the opinion of Danielssen that potassium iodid may be used to determine the cure of leprosy, which would be indicated by absence of a febrile reaction.

General confidence is not felt in the "leprolin" which Rost prepared from his cultures of the leprosy bacillus (?). His cultures are said to have been mixtures of micro-organisms.

Because of the failure to cultivate the leprosy bacillus, experimental work with the serum and cells of man and animals, by which conclusions as to the defensive pow. Susceptibility ers of the body might be drawn, can not be and Means carried out. It seems probable that all men of Defense. are susceptible to leprous infection under the proper conditions. Sauton states that children of from 4 to 5 years are particularly liable to infection. Other conditions which may increase susceptibility are of a conjectural nature. It is possible that leprosy predisposes to tuberculous infection (?).

The condition in leprosy seems to be that of an organism of low virulence against which the body possesses no decisive protective agency. The reactions for the most part are of a local nature, involving the proliferation of connective tissue and blood vessels, and the accumulation of lymphocytes. That phagocytosis by macrophages (lymphocytes, connective tissue, endothelial and ganglionic cells) is a factor which antagonizes the proliferation of the bacilli is suggested by the large number of bacilli which are found in these cells.

The principles of prophylaxis may be illustrated by citing the practices in Norway. Originally all lepers were confined to institutions. At the present time, howProphylaxis. ever, only indigent lepers and those who can not be suitably cared for at home are required to enter an asylum, where they live under the best hygienic conditions. Other patients are allowed to remain at home, with the understanding that they sleep alone and, if possible, have separate rooms, that their clothing, linen and eating utensils be used by no one else, and that proper precautions be taken in the washing of linen. Dressings and bandages must be burned. Under these regulations the number of lepers in Norway has decreased from 2,870 in 1856 to $57 t$ in 1900 . Banishment to a particular island is practiced in the Sandwich Islands. Segregation of lepers should be brought about in this country.

Carasquilla attempted the production of an anti-leprosy serum by immunizing horses with the blood of leprous patients. Although a few favorable reports concerning its effects appeared it has not proved of value in the hands of others.

Truth and the Physician.-You need not tell all the truth unless to those who have a right to know it all. But let all you tell be the truth.-Horace Mann.

\section{Clinfical Reports}

\author{
EPIDERMOID OF THE RIGHT SUBMAXILLARY \\ REGION. \\ VICTOR SCHRAGER, M.D. \\ CHICAGO.
}

The present case is not reported because of its rarity, but simply because of its clinical importance.

Patient.-Physician, male, aged 60.

History.-In the spring of 1898 the patient noticed a small abrasion on the right side of the lower lip. Previous to that time he smoked cigars excessively. In December of the same year he ceased smoking, and by applying a saturated solution of acetanilid to the abrasion, it soon healed. Encouraged by the healing, he began to smoke again. A few months later, in 1899, there was a recurrence of the trouble. In August, 1900, he consulted a surgeon and immediate excision of the lesion was advised. Feeling some uncertainty as to the nature of his trouble, he had a microscopic examination made, and it was found that it was an "incipient epithelioma." In October, 1900 , the epithelioma was cauterized with chromic acid. The ulcer healed, but it left some induration. In the fall of 1902 it recurred, In September, 1904, it was cauterized again with chromic acid and $x$-ray exposures were advised. After fourteen $x$-ray treatments the epithelioma healed very nicely and continued to remain healed.

Examination.-In February, 1905, the patient discovered an oblong swelling below the angle of the right inferior maxilla. He came to Dr. Murphy's office for examination, and an oblong swelling the size of an almond was found, situated as stated above. It was firm of consistency, very slightly movable and adherent to the subjacent tissues. Pressure and manipulation did not cause pain. The patient stated that since the appearance of the swelling he had lost some weight and strength. He also stated that the increase in size was very gradual and slow at first, but that during the last few weeks it bad increased rapidly. Considering the patient had an epithelioma diagnosed by the microscope, his age, the relative wasting symptoms, the situation of the swelling in the 1ymphatic area on the corresponding side, and fixity of the swelling, it was concluded that there was epithelial metastasis in a lymph node. The patient being a physician was not surprised by the diagnosis. He firmly believed that he had a recurrence of carcinoma, and for this reason he was ready to give up his practice and to settle all his affairs in view of future unpleasant events. In spite of his age the man was unusually robust and had no other reason for discontinuing his practice.

Operation.-May 20, 1905, the patient was operated on. The mass had the appearance of a lymph node and was perfectly incapsulated; it was somewhat adherent to the surrounding tissues and was easily enucleated. The patient left the hospital a few days after the operation. The wound healed rather slowly and left an induration in the scar.

Microscopic Examination.-When this specimen was examined in the laboratory an elliptical mass encapsulated in a smooth, intact capsule was found, and a longitudinal incision revealed a whitish pulp containing a cyst cavity in its center. Sections were taken from the pulp and hardened. The microscopic examination of sections showed several undulated layers of epithelial cells, which reproduced perfectly the histologic structure of the skin. Below these layers two three hair follicles and vessels were found the rest of the tissue was occupied by connective tissue and marked round-cell infiltration. No sebaceous glands were found. A diagnosis of infected epidermoid was made. Prof. Robert Zeit based the diagnosis of epidermoid on the absence of sebaceous glands. Had these glands been present the diagnosis would have been dermoid.

Remarks.-This case illustrates the following points:

1. One should not be too positive of diagnosis of epithelial metastasis when a swelling is discovered on the corresponding side of an epithelioma of the lip. Such a mistake may have serious social results, especially in the case of men engaged in active work and of neurotic temperament!

2. The wasting symptoms and the gradual increase in size, 
which are classical elements in the diagnosis of malignant conditions, may be explained in this case by the mental worry of the patient, which is liable to reduce weight, and by the beginning of infection of the epidermoid.

3. Every specimen removed by surgeons should be carefully examined microscopically. At the time of the operation the nodule did not impress the surgeon as being malignant, yet a positive diagnosis could not be made at that time. It is of primary importance that a microscope should be resorted to and the final diagnosis based on the histo-pathologic findings only. Had not this specimen been examined microscopically the case would probably have been recorded as one of permanent cure of carcinoma.

In connection with enlargements or tumors occurring below the inferior maxilla it should be remembered that accessory thyroids may occasionally be found there.

In conclusion I wish to acknowledge my indebtedness to Dr. J. B. Murphy for permitting me to report this case.

\section{UMBILICAL HERNIA PERFORATING THE ABDOMINAL WALL.* \\ MYRON METZENBAUM, B.S., M.D. CLEVELAND, OHIO.}

Patient.-Woman, an imbecile, aged 56, about 3 feet 2 inches in height; weight, 135 pounds.

History.-For more than twenty years it was known that she had an umbilical hernia. During the past four years the hernia was of such proportions as to indicate that it was formed of a very large portion of the small intestines, with a large part of the omentum. The hernia was never reducible; there always remained a considerable portion of the intestines out of the abdominal cavity. The hernial opening permitted only two coils of the bowel to slip by each other.

The woman aided in performing simple household duties, was able to take care of her person to a very fair degree, but under no condition was it possible to train her to wear an abdominal support.

On the evening of March 19, 1904, the people with whom she lived noticed that her outer skirt was wet and attempted to find the cause. They were resisted with such violence as to compel them to abandon the examination. Early on the following morning I was called, and, on entering the room, was almost overcome by the foul odor, suggesting gangrene.

Examination.-The patient was up and about. I induced her to go to bed, and, on removing her clothing, which was thoroughly saturated, the following unusual condition was observed:

The hernia was much larger than usual, causing the abdomen to protrude upward at Jeast ten inches in height. In the region of the umbilicus the abdominal fat has been worn away, so that in this region the bowels were only covered by the skin. Here there was a circular area $21 / 2$ inches in diameter which had become necrotic. At the place where the umbilicus should have been there was a hole fully one inch in diameter, throngh which the umbilicus and what I thonght to he the urachus dangled out on to the abdomen. No attempt was made to reruce the bowel, but a binder was fastened around the abdomen and the patient was removed at once to the Mt. Sinai Hospital for immediate operation.

Up to that time she had not romited. Her pulse was about 86 ; temperature normal. She did not seem to be suffering the slightest pain and, judging by her features alone, one would not know that anything was ailing her. She had eaten some breakfost and wanted to engage in her usual duties. The servant was of the opinion that her bowels had moved on the previous day.

From these symptoms I did not consider that there was either strangulation or torsion of the bowel, but that a greater amount of the bowel than usual had been forced through the

* Read before the Cleveland Academy of Medicine, 100. abdominal opening, causing a very great pressure on the thin abdominal skin and produeing necrosis.

Operation.-Within an hour from the time I first saw the patient she was on the operating table. With the kind services of Dr. C. A. Hamann, the following operation was performed and the following conditions observed:

Nearly all the small intestines, together with the cecum and appendix and a large portion of the omentum, comprised the hernia. Loops of intestines were grown together with masses of the abdominal fat and omentum, and in many places were firmly adherent to the abdominal wall itself. It was for these reasons that the hernia was never reducible.

The opening in the abdominal wall was not over $1 \frac{1}{2}$ inches in diameter, so that the cecum, once being forced through, could not slip back into the abdominal cavity. That which 1 had considered the urachus dangling through the perforation was a Meckel's diverticulum. This was gangrenous and was amputated, as well as part of the omentum. The bowel itself seemed healthy. The fluid which saturated her clothing was peritoneal fluid and serum exudate from the bowel.

After long and tedious work, the various adhesions of the bowel were broken up, but only after unusual effort was it pos. sible to replace the intestines in the abdominal cavity.

Postoperative History.-The abdominal opening was closed. The time required for the operation was one hour and forty minutes. The patient was returned to bed, and soon it became necessary to administer artificial respiration and frequently thereafter, for it seemed as though her respiratory center was interfered with in a very marked degree. She rallied from the operation, her bowels moved at the end of twenty-four hours, she took considerable nourishment, and became about as in. telligent as ever. On the third day a double lobar pneumonia developed, and she died on the evening of the fourth as a direct result of the pneumonia. Up to this time the abdomen remained flat, with no unusual tenderness or soreness and no evidence of peritonitis.

\section{GUNSHOT WOUND OF THE BOWELS.}

\section{O. S. HUTCHINS, M.D.
CANBY, MINN.}

Patient.-June 18, 1905, a girl, 13 years of age, while carelessly handling a 22 -caliber rifle, shot herself in the abdomen one and one-half inches to the right and slightly below the middle of a line drawn from the umbilicus to the os pubis. She resided at a farmhouse ten miles in the country. Patient had vomited before I reached her, four hours after the accident, and was in considerable pain with limbs drawn up. There was increased pain on slight pressure over the bowels. Considerable shock was present.

operation.-Preparation for operation was commenced immediately. Under anesthetic, median incision was made into peritoneum. Considerable free and clotted blood was found, which was scooped out. The first loop of bowel in region of entrance of bullet into peritoneum was grasped, pulled out, and six openings in the small bowel were found in searching nearly its whole length. The openings were closed with Lembert sutures of linen (Pagenstecher). The cecum was then examined and a slit one and one-half inches long near the appendix was found penetrating all the coats of the bowel. A picce of feces which projected from the opening was removed with gauze sponge and this opening was closed as before. Drainage was introduced down to the points of suture in cecum and intestines; also into cul-de-sac of Douglas.

Convalescence.-Bowels moved on third day after repeated small doses of calomel followed by enema. Drainage was gradually removed after the third day. Temperature remained from 99 to 101 for three weeks, when swelling deve]oped above the lower third of Poupart's ligament, and in a few days an abscess discharged through the opening left for drainage. After this there was an uninterrupted recovery. Patient was out of bed at the end of the sixth week with small fistulous opening at lower angle of wound, which had completely closed two weeks later. Bullet was not searched
for. 